Q

Check for

updates

Cite as

Nano-Micro Lett.

(2022) $14: 72$

Published online: 7 March 2022

(C) The Author(s) 2022

\section{Correction to: Nb2C MXene-Functionalized Scaffolds Enables Osteosarcoma Phototherapy and Angiogenesis/Osteogenesis of Bone Defects}

Junhui Yin ${ }^{1,4}$, Shanshan Pan ${ }^{2,3}$, Xiang Guo ${ }^{5}$, Youshui Gao ${ }^{4}$, Daoyu Zhu ${ }^{4}$, Qianhao Yang ${ }^{4}$, Junjie Gao ${ }^{4}$, Changqing Zhang ${ }^{1,4} \bowtie$, Yu Chen ${ }^{2,3} \bowtie$

The original article can be found online at https://doi.org/10.1007/s40820-020-00547-6 Junhui Yin and Shanshan Pan have contributed equally to this work..

$\square$ Junjie Gao, colingjj@163.com; Changqing Zhang, zhangcq@sjtu.edu.cn; Yu Chen, chenyuedu@ shu.edu.cn

1 Institute of Microsurgery On Extremities, Shanghai Jiao Tong University Affiliated Sixth People's Hospital, Shanghai 200233, People's Republic of China

2 School of Life Sciences, Shanghai University, Shanghai 200444, People's Republic of China

3 State Key Laboratory of High Performance Ceramics and Superfine Microstructure, Shanghai Institute of Ceramics, Chinese Academy of Sciences, Shanghai 200050, People's Republic of China

4 Department of Orthopaedic Surgery, Shanghai Jiao Tong University Affiliated Sixth People's Hospital, Shanghai 200233, People's Republic of China

5 Department of Orthopedics, The Second Affiliated Hospital, The Navy Medical University, Shanghai 200003, People's Republic of China
Correction to: Nano-Micro Lett. (2021) 13:30

https://doi.org/10.1007/s40820-020-00547-6

The original version of this article unfortunately contain some mistakes in figure. The authors found that the curves in Fig. 1f, g were missing.

The corrected version of Fig. 1 is given below: 

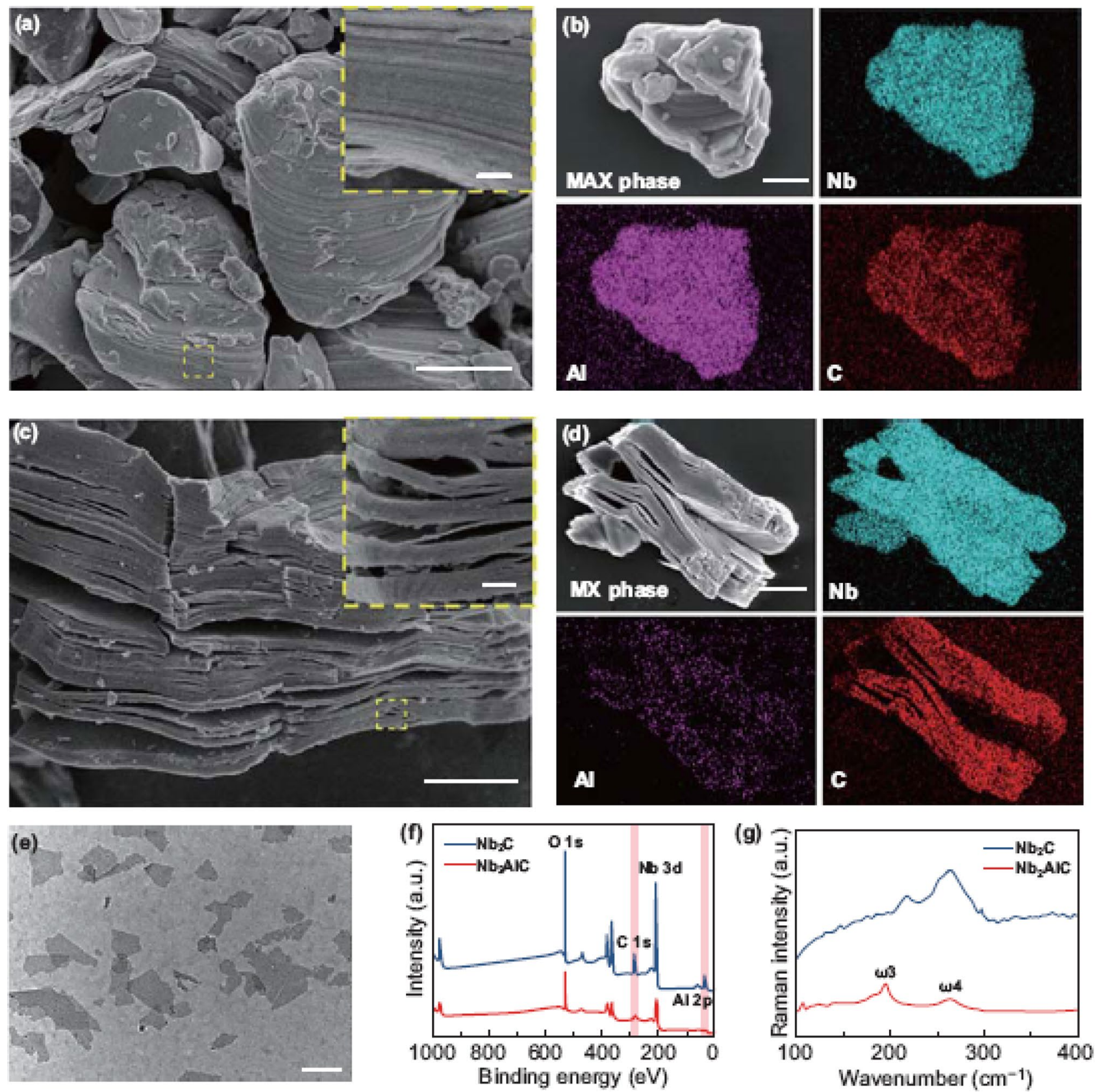

Fig. 1 Fabrication and characterization of ultrathin 2D Nb${ }_{2} \mathrm{C}$ MXene NSs. a, b SEM images of $\mathrm{Nb}_{2} \mathrm{AlC}$ ceramics with corresponding element mapping $(\mathrm{Nb}, \mathrm{Al}$ and $\mathrm{C})$. c, d SEM images of multilayered $\mathrm{Nb}_{2} \mathrm{C}$ MXene and the corresponding element mapping ( $\mathrm{Nb}, \mathrm{Al}$ and $\left.\mathrm{C}\right)$. e TEM image of one-layered or few-layered $\mathrm{Nb}_{2} \mathrm{C}$ MXene NSs. f X-ray photoelectron spectroscopy (XPS) spectra of $\mathrm{Nb}_{2} \mathrm{AlC}$ bulk and $\mathrm{Nb}_{2} \mathrm{C} \mathrm{NSs}$. $\mathrm{g}$ Raman spectra of $\mathrm{Nb}_{2} \mathrm{AlC}$ bulk and $\mathrm{Nb}_{2} \mathrm{C}$ NSs. The scale bar in plane a-c equals $1 \mu \mathrm{m}$, and the bar of inset a and $\mathbf{c}$ represents $100 \mathrm{~nm}$. The scale bar in plane $\mathbf{e}$ is $200 \mathrm{~nm}$. (Color figure online)

Open Access This article is licensed under a Creative Commons Attribution 4.0 International License, which permits use, sharing, adaptation, distribution and reproduction in any medium or format, as long as you give appropriate credit to the original author(s) and the source, provide a link to the Creative Commons licence, and indicate if changes were made. The images or other third party material in this article are included in the article's Creative
Commons licence, unless indicated otherwise in a credit line to the material. If material is not included in the article's Creative Commons licence and your intended use is not permitted by statutory regulation or exceeds the permitted use, you will need to obtain permission directly from the copyright holder. To view a copy of this licence, visit http://creativecommons.org/licenses/by/4.0/. 